\title{
Uma comparação entre a percepção das universidades/institutos de pesquisa e das empresas sobre o processo de interação
}

Walter Tadahiro Shima ${ }^{1}$

Fabio Doria Scatolin ${ }^{2}$

Resumo: O objetivo principal do trabalho é investigar a percepção dos principais atores envolvidos no processo de interação universidade empresa no Brasil. Isto é analisar como os dois segmentos (U/E) entendem a relação do ponto de vista das dificuldades, interesses e resultados $\mathrm{O}$ artigo discute a partir de informações extraídas da base de dados da pesquisa Brazil Survey, o padrão das relações universidade-indústria no Brasil. Os dados recolhidos da pesquisa de campo sugere a importância da interação entre universidade indústria para o processo de inovação no Brasil. Ambas, as empresas e universidades concordam que no caso brasileiro, as patentes não são importantes para a interação e para o processo de inovação. Por outro lado a interação mais informal, como o encontro de intercâmbio, publicações e pesquisas são mais importantes para ambos atores.

Palavras-chave: relações universidade-indústria; pesquisa colaborativa; interação universidade-indústria; inovação.

JEL: O18; O31; R12.

1 Professor do Programa de Pós-Graduação em Políticas Públicas da Universidade Federal do Paraná (UFPR). E-mail: waltershima@ufpr.br

2 Professor do Programa de Pós-Graduação em Políticas Públicas da Universidade Federal do Paraná (UFPR). E-mail: scatolin@ufpr.br 


\title{
A comparison between the perceptions of the interaction process of universities/ research institutes and companies
}

\begin{abstract}
The main goal of the paper is to investigate how collaborative university-industry interactions occur in Brazil. That is to analyze how the two segments $(U / E)$ understand the relationship from the point of view of the difficulties, interests and results. The article discusses based on information extracted from the database of the Survey Research Brazil, the pattern of university-industry relations Brazil. The field research of university-industry colaboration suggests the importance of the interaction for the innovation process in Brazil. Both firms and university agree that in Brazilian case, patents are not importante for interaction and for the innovation process. On the other hand more informal interaction like exchange meeting, publications and surveys are more importante for boths actors.
\end{abstract}

Key-words: University industry relations; Colaborative research; Innovation; University industry interaction.

JEL: O18; O31; R12.

\section{Introdução}

Um número crescente de países desenvolvidos e mesmo em desenvolvimento passaram a implementar políticas de apoio ao fortalecimento dos vínculos entre Universidade e empresas nos últimos anos. A principal racionalidade para este tipo de política de Ciência e Tecnologia (C\&T) tem sido a crença na importância das inovações para o crescimento das nações. Dentro desta perspectiva de um lado a universidade e/ou os centros de pesquisas governamentais e de outro lado as firmas principalmente do setor manufatureiro e de tecnologia da informação (TI) tem ampliado esta cooperação com o objetivo de acelerar a introdução as inovações na estrutura produtiva. O problema central aqui é que os motivos desta cooperação bem como os resultados desta cooperação não estão claros para a sociedade como um todo nem para os próprios atores. Decorridos mais de 50 anos do trabalho seminal de Vannevar Bush sobre a relação entre a pesquisa básica e o desenvolvimento de produtos, algumas questões permanecem em aberto segundo Cohen (2002, p. 4). Qual é a extensão do impacto da produção acadêmica na pesquisa e no desenvolvimento industrial? Quais são os principais canais de interação destes atores e quais os seus resultados?

O presente artigo analisa a interação dos Grupos de Pesquisa (GP) das universidades e as empresas no Brasil a partir da percepção destes atores. Os resultados desta pesquisa estão baseados em pesquisa de campo coletada junto aos pesquisadores das universidades que reportaram relações com empresas junto ao diretório do Conselho Nacional de Desenvolvimento Científico e Tecnológico (CNPq) e junto a empresas nacionais e multinacionais 
instaladas no Brasil que reportaram alguma relação com as universidades/ institutos de pesquisa em 2006 e 2009, respectivamente. Como já foi reportado em diversos artigos publicados no âmbito dessa pesquisa, dos questionários aplicados aos grupos do diretório de pesquisa do CNPq que mantinham relação com empresas, responderam no Brasil ao todo 1005 grupos e dentro das empresas 325 responderam. Foi aplicado um questionário próprio para os GPs e outro para as empresas. O questionário destinado aos GPs continha questões especificas buscando captar a sua visão do processo de interação universidade-empresa (U/E), sendo o mesmo sendo feito no questionário aplicado às empresas. Porém, algumas questões se repetiram para os dois lados e o que permitiu um confronto das duas visões e percepções sobre o mesmo tema. Nesse artigo o objetivo é analisar como os dois segmentos (U/E) entendem a relação do ponto de vista das dificuldades, interesses e resultados.

O presente artigo esta estruturado da seguinte forma. Na $1^{\mathrm{a}}$ seção após esta introdução apresenta-se uma breve discussão da literatura sobre os determinantes da interação universidade-empresa e as suas motivações. A $2^{\text {a }}$ seção está subdividida em subseções e apresenta os resultados da pesquisa com os GPs das universidades e institutos de pesquisa (U/I) que reportaram relações com empresas e do questionário com empresas que reportaram relações com as universidades e institutos de pesquisas. Na subseção 2.1 compara-se a relevância das fontes de informações para U/E; na subseção 2.2 discute-se como a universidade e a empresa entendem os resultados e benefícios do relacionamento; na subseção 2.3 busca-se entender as razoes do porque elas colaboram; na subseção 2.4 verifica-se a quem a interação U/E atribui o inicio da aproximação e relacionamento; na subseção 2.5 avaliam-se as razoes dos insucessos na interação a partir da ótica dos dois principais atores; na 2.6 procura-se entender como as universidades e as empresas entendem a função da outra instituição, e finalmente $\mathrm{n}$ a subseção 2.7 compara-se a contribuição das diferentes áreas do conhecimento com o número de grupos de pesquisas envolvidos na interação; e na seção $3^{\mathrm{a}}$ algumas conclusões são apresentadas.

\section{A interação entre universidade e empresa e a inovação}

Historicamente o papel da ciência básica tem sido reconhecido como fonte importante para a inovação produzida pelas empresas. De um modelo "linear" elaborado por Vannevar Bush nos anos 40 do século passado, onde a relação fluía unicamente das universidades e institutos de pesquisa em direção às empresas, o conhecimento científico sobre a relação das universidades com as empresas e o processo de inovação evoluiu consideravelmente nas ultimas décadas. Uma nova concepção desta relação tem emergido dos trabalhos de Gibbons \& Jonston (1975), Nelson (1990), Stokes (1997) e Cohen et al (2002), 
onde a inovação surge de uma interação mais complexa entre Universidade e Institutos de pesquisas e as Empresas (U/IP-E). Ora os problemas das empresas auxiliam o avanço do conhecimento nas universidades, ora o conhecimento das universidades desempenham um papel relevante. Neste novo processo o elemento central é a interação existente U/IP-E. A questão central aqui é que os motivos desta cooperação bem como os resultados desta cooperação não estão claros para a sociedade e mesmo para os pesquisadores da área. Em um provocante artigo de Veugerles \& Cassiman (2005) sugerem que, do ponto de vista da empresa, a cooperação com universidade e institutos de pesquisa governamental é apenas um dos elementos de sua estratégia inovativa. Outras relações com os clientes e fornecedores desempenham papel central neste processo. As evidencias sugerem ainda um positivo efeito da cooperação entre empresa e universidade através da produção de conhecimento principalmente da pesquisa pública para a indústria de transformação (Veugerles \& Cassiman, 2005).

Outros trabalhos como Cohen et al (2002) sugerem mais especificamente que a pesquisa pública é crucial em poucos setores industriais como o setor farmacêutico e afeta de maneira importante a Pesquisa e Desenvolvimento (P\&D) dos demais setores manufatureiros. Seus resultados sugerem ainda que a pesquisa pública não só possibilita a geração de novas idéias para o setor manufatureiro como auxilia a solução de problemas existentes na indústria das mais diversas formas possíveis. Os resultados evidenciam também que quase $1 / 3$ dos projetos de P\&D industrial fizeram uso das descobertas feitas pela pesquisa pública e que o efeito do conhecimento originado dessa pesquisa tem um efeito tão grande quanto o spillover intra-industrial decorrente do conhecimento originado de P\&D dos rivais. Ou seja, a P\&D decorrente do processo competitivo tem uma relevância no crescimento da produtividade.

Suzigan e Albuquerque (2010) discutindo tanto o caso dos países desenvolvidos como o caso dos países em desenvolvimento sugerem que a construção desta interação universidade e empresa é um longo processo histórico que exige investimento e maturação em pelo menos cinco dimensões:

1. Preparação do arranjo monetário e financeiro a fim de tornar viável a criação e financiamento de universidades, institutos de pesquisa e firmas;

2. Construção de instituições relevantes como universidades, institutos de pesquisa e firmas;

3. Construção de mecanismos que possam aproximar estes dois segmentos com o intuito de criação de dialogo entre estas instituições;

4. Desenvolvimento de interações entre as partes (learning by interaction) através de um processo de tentativa e erro; e,

5. Desenvolvimento e consolidação desta interação criando confiança mutua e possibilitando um feedback positivo entre estas instituições. 
Com três estudos de caso (soja, aço e aviões) os autores sugerem que o papel da Universidade e dos institutos de pesquisa governamentais tem sido subestimado no caso Brasileiro. Em outro trabalho Fernandes et al (2010) analisando o caso brasileiro encontraram evidencias que canais bidirecionais são particularmente relevantes para os atores (U/IP-E), produzindo resultados positivos em termos de inovação e produtos para as firmas e benefícios intelectuais e econômicos para as universidades e institutos de pesquisa.

\section{Análise dos resultados: uma comparação entre a visão das universidades/institutos de pesquisa e das empresas}

Algumas questões dos questionários aplicados às empresas e aos grupos de pesquis foram formuladas de maneira idêntica aos dois atores e outras questões não foram exatamente as mesmas, mas podem ser interpretadas de forma que se possa buscar uma comparação entre elas. Como já se ressaltou acima, esse é objetivo do artigo. Isto é, de um lado comparar as respostas das empresas e de outro lado as respostas dos GPs e analisar suas perspectivas sobre como esses dois atores se relacionam. A seguir comparase o comportamento das respostas das empresas e dos grupos de pesquisa sobre os diversos aspectos abordados nos questionários. Algumas questões contemplavam respostas qualitativas com quatro possibilidades de resposta: 1. Sem importância; 2. Pouco Importante; 3. Moderadamente importante e 4. Muito importante. Para facilitar a visualização dos gráficos e dar uma noção de relevância mais clara das respostas, nesse artigo, as respostas foram agrupadas em dois grupos:

1. Sem importância +2 . Pouco Importante $=1$ (importância baixa).

3. Moderadamente importante +4 . Muito importante $=2$ (importância alta).

\subsection{Principais fontes de informação - patentes, troca informal de informações e publicações e relatórios}

As empresas pesquisadas responderam a respeito das fontes de informação sobre outras empresas, universidades e grupos de pesquisas. Os GPs responderam sobre os canais de informação para transferência de conhecimento do grupo para as empresas. Das diversas fontes de informação listadas, as fontes patentes, troca informal de informações e publicações e relatórios apresentaram o mesmo grau de relevância tanto para as empresas como para os GPs. Para os dois atores as patentes foram consideradas como 
de importância baixa (sem importância/pouco importante = 1) como fonte de informação para as atividades inovativas e aumentar o conhecimento das empresas sobre outras empresas, universidades e institutos de pesquisas (U/IP). Da mesma forma, as patentes não foram consideradas mecanismos relevantes para as universidades (GPs) transferirem conhecimento às empresas. Uma explicação possível para isso está no fato de que o numero de patentes no país é baixo comparativamente a grande parte dos países desenvolvidos/emergentes, conforme apontam Ginarte e Park (1997) e Lall (2003), portanto, elas não são fontes que disponibilizariam um volume abundante de informações relevantes, de acordo com as Figuras 1 e 2.

FIGURA 1. EVOLUÇÃO DO TOTAL DE NÚMERO DE PATENTES POR PAÍS DE ORIGEM - 1999-2008

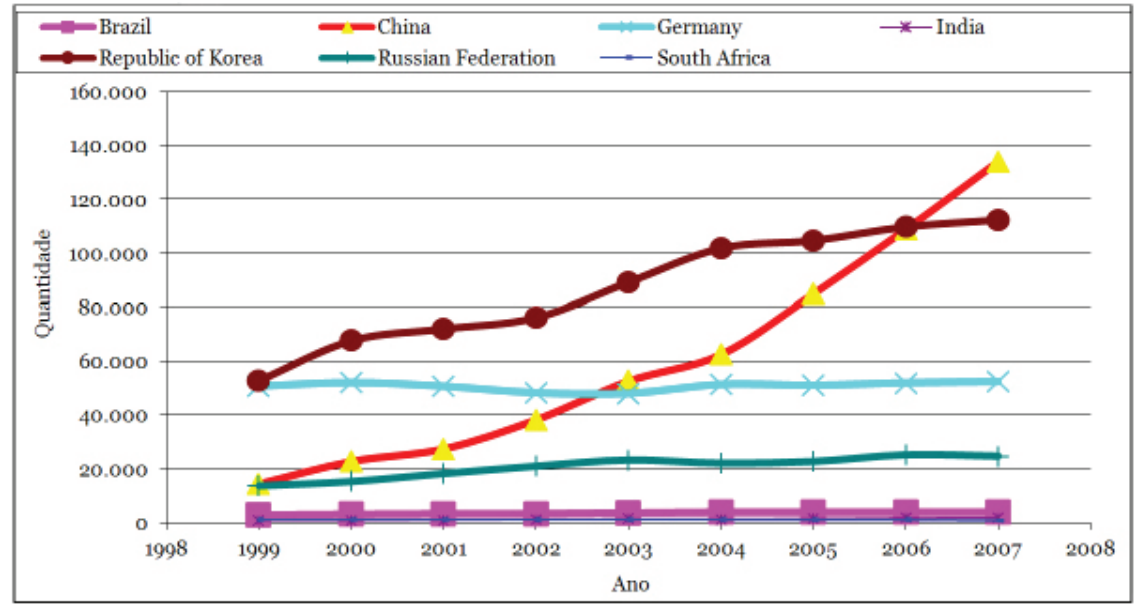

FONTE: elaborado pelos autores. Disponível em: http://www.wipo.int/ipstats/en/statistics/patents. 
FIGURA 2. GRAU DE IMPORTÂNCIA DAS FONTES DE INFORMAÇÃO PATENTES - 2006-2009

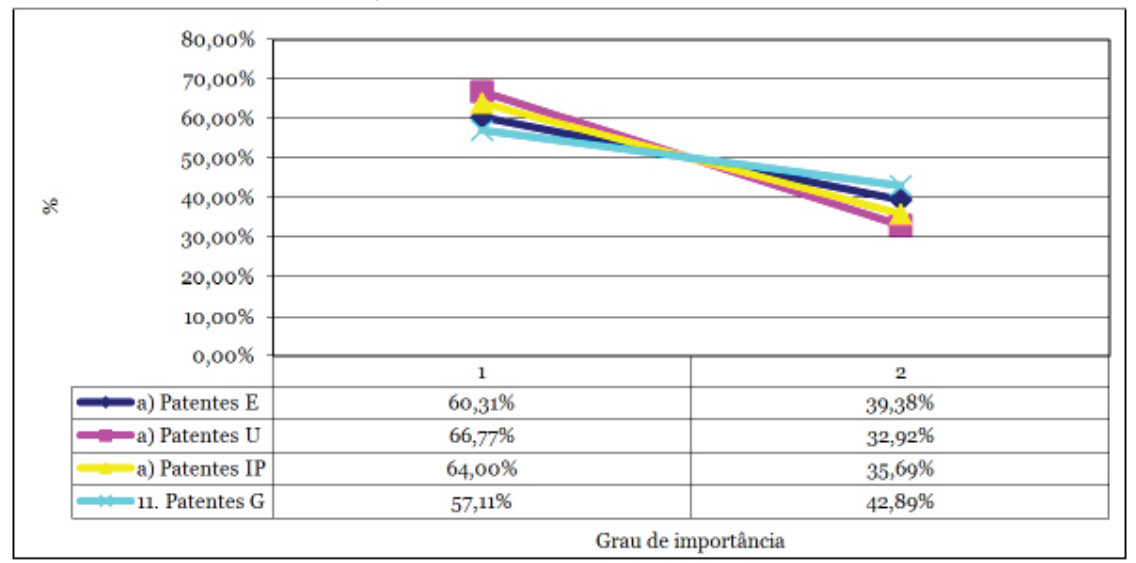

FONTE: elaborado pelos autores. Disponíveis em: http://www.wipo.int/ipstats/en/statistics/patents.

Por outro lado, as empresas e os GPs das universidades concordaram que a troca informal de informações e publicações e relatórios são relevantes para a aquisição de informações (Moderadamente importante/Muito importante = 2). A primeira fonte corrobora o fato de que a relação U-E implica proximidade pessoal entre técnicos das empresas e os pesquisadores, uma vez que, parte importante do conhecimento gerado e transmitido na relação tem um elevado componente tácito. Esse caráter tácito somente é possível ser compartilhado a partir da informalidade dado que permite melhor fluência da dinâmica de trabalho e, em grande parte, gera novos temas de pesquisa e razoes para continuidade da interação, conforme as Figuras 3 e 4.

FIGURA 3. GRAU DE IMPORTÂNCIA DAS FONTES DE INFORMAÇÃO, TROCA INFORMAL DE INFORMAÇÕES - 2006-2009

\begin{tabular}{|c|c|c|}
\hline \multirow{6}{*}{$\begin{array}{r}80,00 \% \\
70,00 \% \\
60,00 \% \\
50,00 \% \\
40,00 \% \\
30,00 \% \\
20,00 \% \\
10,00 \% \\
0,00 \%\end{array}$} & \\
\hline & & \\
\hline & \\
\hline & & \\
\hline & \\
\hline & 1 & 2 \\
\hline $\begin{array}{c}\text { d) Troca informal de } \\
\text { informações E }\end{array}$ & $31,69 \%$ & $68,00 \%$ \\
\hline $\begin{array}{c}\text {-d) Troca informal de } \\
\text { informações U }\end{array}$ & $38,15 \%$ & $61,54 \%$ \\
\hline $\begin{array}{c}\text { d) Troca informal de } \\
\text { informações IP }\end{array}$ & $45,54 \%$ & $54,15 \%$ \\
\hline $\begin{array}{c}\text { 14. Troca informal de } \\
\text { informação }\end{array}$ & $34,03 \%$ & $65,97 \%$ \\
\hline \multicolumn{3}{|c|}{ Grau de importância } \\
\hline
\end{tabular}

FONTE: pesquisa de campo. 
FIGURA 4. GRAU DE IMPORTÂNCIA DAS FONTES DE INFORMAÇÃO, PATENTES - PUBLICACCÕES E RELATÓRIOS - 2006-2009

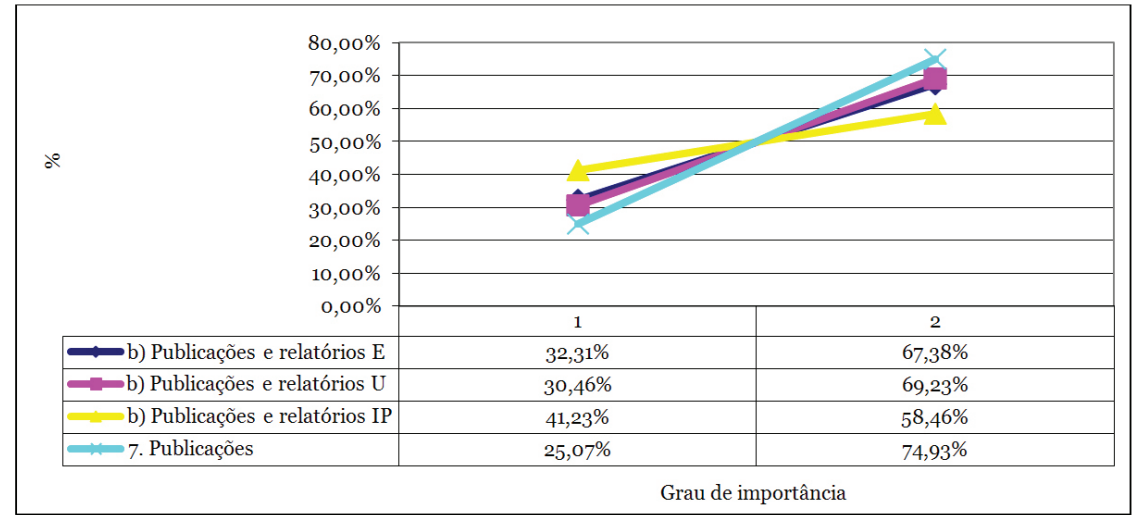

FONTE: pesquisa de campo.

A segunda fonte assume elevada importância em função de que se trata da instância onde mais se disponibilizam informações relevantes às atividades inovativas. Isto é, ao contrário das patentes o volume de produção técnocientífico tem se expandido no país de forma bastante significativa, o que significa que o crescimento do conhecimento científico ainda não tem se materializado, na mesma proporção, em novas tecnologias. Isso pode ser visto na Figura 5. Daí a provável razão porque as patentes não são fontes relevantes de informação para empresas e GPs.

FIGURA 5. EVOLUÇÃO DO NUMERO DE ARTIGOS E PATENTES NO BRASIL - 1979 - 2009

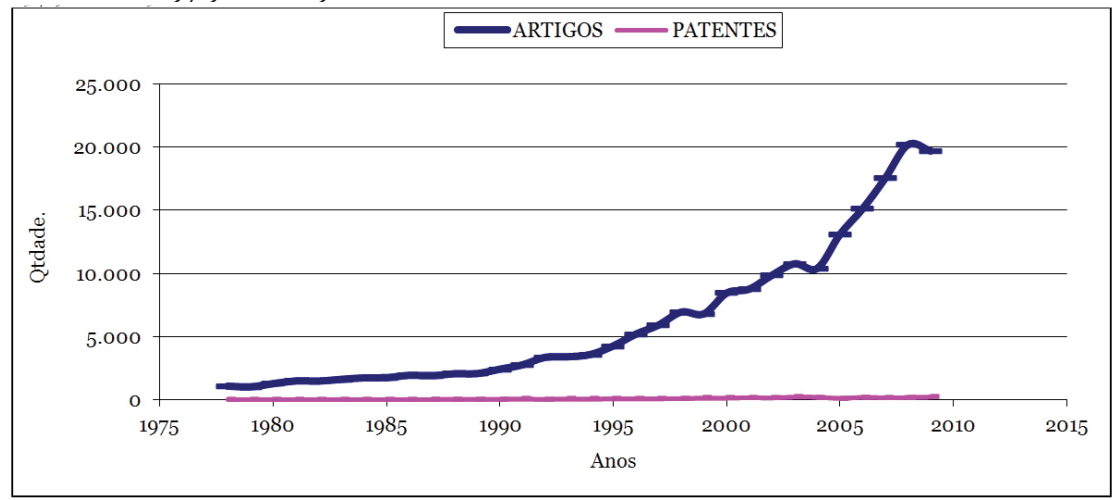

FONTE: Pulido, 2011. 


\subsection{Uso dos resultados produzidos por U/IP e os resultados e beneficios da interação com empresas para os GPs das universidades e institutos de pesquisas}

Outro conjunto de questões aplicadas às empresas se referia a como eram usadas para as atividades inovativas os resultados produzidos por U/IP. Pelo lado dos GPs as questões levantadas se referiam aos resultados e benefícios que o relacionamento com empresas produziam para elas. Significa dizer que, por um lado, as empresas usam os resultados produzidos pelas U/IP e em contrapartida isso também poderia implicar algum resultado e beneficio para os GPs. Portanto, esperava-se que o grau de importância atribuído pelas empresas aos diversos resultados produzidos pelas U/IP implicava o mesmo grau aos resultados e benefícios por parte das universidades e institutos. Nesse sentido, dentro da questão aplicada ás empresas e aos GPs entendiase que o grau de importância atribuído ao resultado de pesquisa para as empresas deveria implicar novas descobertas científicas, novos projetos de pesquisa, novos produtos e artefatos, novos processos industriais, idéias para novos projetos de cooperação e novos projetos de pesquisa. De acordo com Figura 6, o uso dos resultados de pesquisas por parte das empresas não implicava novos processos industriais. Em outros termos, as empresas usavam muito os resultados produzidos pelas U/IP ao mesmo tempo em que isso resultava em benefícios relevantes para os GPs, com exceção de novos processos industriais.

Por outro lado, acredita-se que os Protótipos produzidos pelas U/IP deveriam implicar para os GPs design, melhoria de produtos industriais, patentes e software. Porém, apesar de que isso possa ser verdadeiro, uma vez, que as empresas não usavam os protótipos para suas atividades isso não resultava em benefícios para os GPs. Assim sendo, se os GPs produziam protótipos eles não eram relevantes para a inovação dentro das empresas e consequentemente, não implicavam benefícios relacionados para os GPs. Tanto empresas como GPs atribuíam importância nula/baixa aos resultados, segundo a Figura 7.

Porém, as empresas atribuem importância alta ao uso de laboratórios/ metrologia das U/IP, considerando que, por conta, da dinâmica de ensino e pesquisa estes sejam bastante bem equipados, o que não é o caso da maioria das empresas em geral. Ao mesmo tempo, os GPs atribuem o mesmo grau de importância ao uso de equipamentos/instrumentos de uso compartilhado. Esse tipo de compartilhamento é provável que tenham esse tipo de elevada relevância em grande parte, em função do relacionamento informal. Uma vez que, a troca informal de informações é importante para ambos, isso se materializa em parte na troca e uso compartilhado de instrumentos e laboratórios. Portanto, a elevada troca informal de informações leva ao alto uso compartilhado de instrumentos e laboratórios, conforme a Figura 8. 
FIGURA 6. USO DOS RESULTADOS PRODUZIDOS PELAS EMPRESAS x RESULTADOS E BENEFÍCIOS PARA OS GPs - 2006-2009

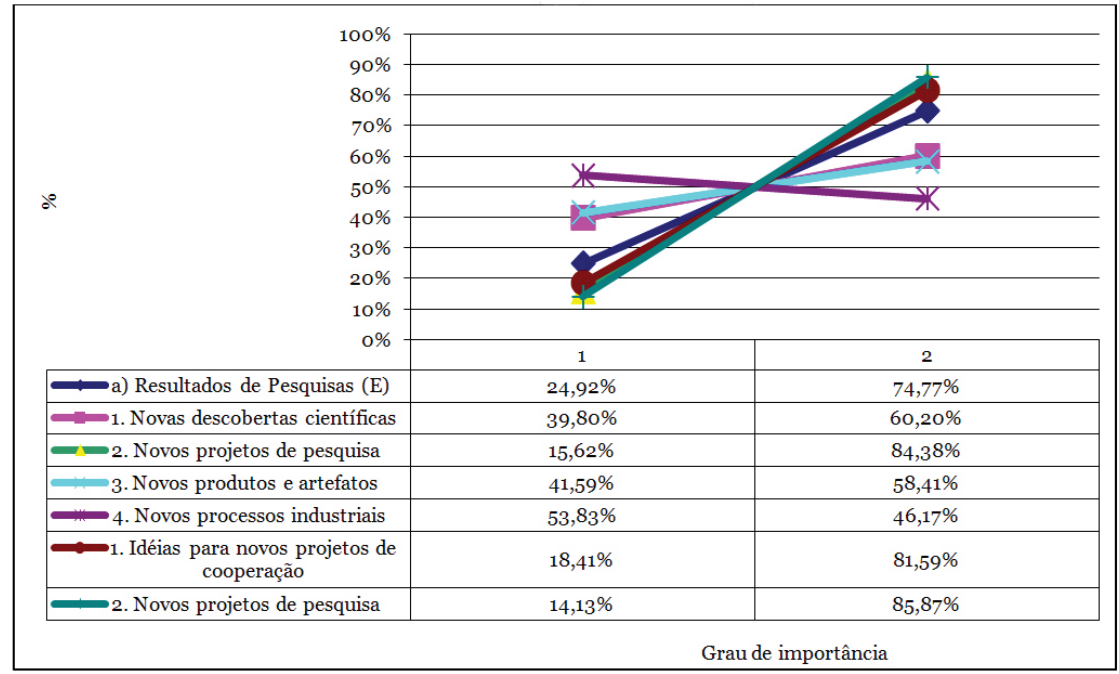

FONTE: pesquisa de campo.

FIGURA 7. PROTÓTIPOS x DESIGN, MELHORIA DE PRODUTOS INDUSTRIAIS, PATENTES E SOFTWARE PELAS GPS - 2006-2009

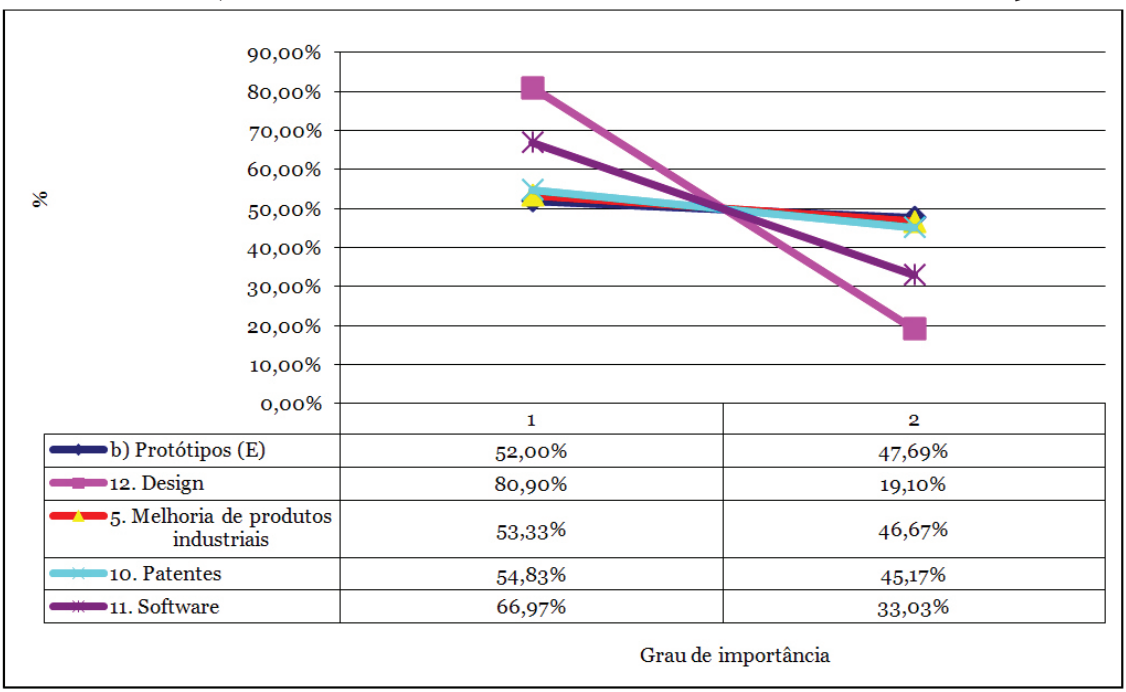

FONTE: pesquisa de campo. 
FIGURA 8. LABORATÓRIOS/METROLOGIA X EQUIPAMENTOS/ INSTRUMENTOS DE USO COMPARTILHADO PELAS GPS - 2006-2009

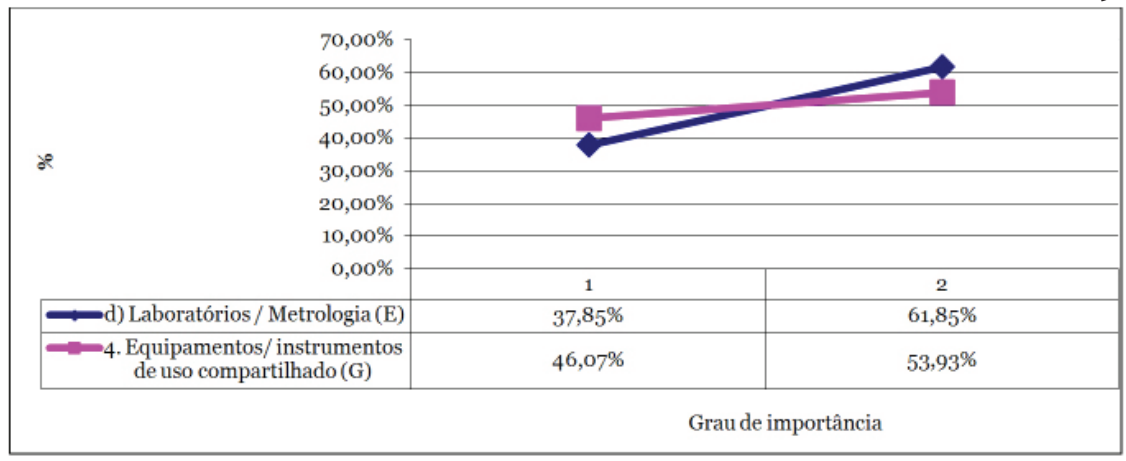

FONTE: pesquisa de campo.

\subsection{Razões da colaboração das empresas com universidades e institutos (U/IP) e os beneficios do relacionamento com empresas para os GPs das universidades e institutos de pesquisa}

As empresas colaboram porque buscam algum produto/serviço/conhecimento que a relação pode produzir. Ou seja, buscam algum tipo de beneficio para as suas atividades inovativas. Do lado das U/IP, os GPs também somente entram na relação se ela implicar resultados e benefícios. Desse modo, na medida em que as empresas buscam transferência de tecnologia da universidade, supostamente os GPs farão a transferência se tiverem a possibilidade de novas descobertas científicas, novos produtos e artefatos, novos processos industriais, patentes e software, conforme a Figura 9. Entretanto, a transferência de tecnologia para as empresas que tem importância media/ alta como razão para a relação com as U/IP, do lado das U/IP implica apenas novas descobertas científicas e novos produtos e artefatos. Como já destacado anteriormente, os GPs atribuem importância nula/baixa a novos processos industriais, patentes e software. Nestes termos, não é em razão desses últimos que os GPs buscam colaboração.

O relacionamento U-E é importante porque possibilita a geração de temas concretos e aplicados para a produção teses e dissertações, publicações e novas redes de relacionamento. Esses 3 elementos tem uma importância média/ alta como razão do relacionamento por parte dos GPs. Do ponto de vista das empresas esses elementos, que se referem á produção de conhecimento/ informação poderiam ser traduzidos como conseguir informações sobre engenheiros ou cientistas e/ou tendências de P\&D nas áreas científicas, uma vez que, teses e dissertações, publicações e novas redes de relacionamento produziriam esses tipos de informação. Entretanto, as empresas atribuem 
importância 1 a esses elementos como razão do relacionamento. Assim sendo, não é para obter informações/conhecimentos científicos que produzem teses e dissertações, publicações e novas redes de relacionamento objeto de interesse dos GPs que as empresas cooperam. Portanto, nesse sentido, quando há cooperação a razão não está relacionada à produção do conhecimento por parte das empresas, mas sim por parte dos GPs, conforme a Figura 10.

Do ponto de vista das empresas isso tem razão de ser, dado que elas estão diretamente interessadas no uso das capacitações dinâmicas das U/IP para a resolução de problemas tecnológicos do que a produção científica. Por exemplo, tanto para empresas como para GPs tem importância média/alta utilizar recursos disponíveis nas universidades e laboratórios de pesquisa, no caso das empresas, assim como equipamentos/instrumentos de uso compartilhado, por parte dos GPs. Significa dizer que as empresas têm interesse no uso da ampla infra-estrutura tecnológica disponível nas U/IP que responde prontamente às suas necessidades do ponto de vista hard e solução de problemas. Por outro lado, alem da produção do conhecimento cientifico, não necessariamente vinculado a resolução de problemas, os GPs também têm interesse em compartilhar equipamentos e instrumentos, dado que, obviamente, a relação com empresas gera conhecimentos aplicados e básicos, daí se explica o interesse na relação para a produção de teses e dissertações, publicações, exposto na Figura 11.

Outro exemplo. Enquanto as empresas atribuem importância media/alta a contratar pesquisas complementares, necessárias para as atividades inovativas da empresa em universidades e institutos, centros ou laboratórios de pesquisa e contratar pesquisas que a empresa não pode realizar, o que corrobora a idéia de que a infra-estrutura das U/IP são amplamente necessárias às empresas, os GPs estão atribuem o mesmo grau de importância (com percentuais maiores ainda) a novos projetos de pesquisa, idéias para novos projetos de cooperação e novos projetos de pesquisa, segundo a Figura 12. Nestes termos, enquanto as empresas cooperam para resolver seus problemas em termos até de pesquisa aplicada, os GPs cooperam para produzir novos conhecimentos. Os interesses têm um foco um pouco diferenciado entre as duas instâncias, mas a forma de se chegar a seus objetivos implica a cooperação. Isso pode ser visto na Tabela 1 em que segundo os GPs os tipos de relacionamento com maior importância média/alta são os mais relacionados à aplicabilidade imediata dentro das empresas. Ao mesmo tempo, conforme Nelson (1986) e Klevorick et al (1995) citados por Cohen et al (2002) isso ocorre porque as empresas percebem que as descobertas muito recentes têm pouco efeito na indústria (fora poucas indústrias intensivas em tecnologia como drogas e outras áreas da medicina). 
TABELA 1. GRAU DE IMPORTÂNCIA TIPOS DE RELACIONAMENTO SEGUNDO OS GPs - 2006-2009

\begin{tabular}{|c|c|c|}
\hline Tipo de relacionamento & Baixa & Alta \\
\hline $\begin{array}{l}\text { Projetos de P\&D em colaboração com a empresa, } \\
\text { com resultados de uso imediato }\end{array}$ & $31,44 \%$ & $68,56 \%$ \\
\hline Consultoria & $32,44 \%$ & $67,56 \%$ \\
\hline Treinamento e cursos & $37,31 \%$ & $62,69 \%$ \\
\hline $\begin{array}{l}\text { Avaliações técnicas, estudos de viabilidade, } \\
\text { gerenciamento de projetos }\end{array}$ & $43,38 \%$ & $56,62 \%$ \\
\hline $\begin{array}{l}\text { Projetos de P\&D complementares às atividades } \\
\text { de inovação da empresa }\end{array}$ & $46,07 \%$ & $53,93 \%$ \\
\hline $\begin{array}{l}\text { Projetos de P\&D em colaboração com empresas, } \\
\text { sem resultados de uso imediato }\end{array}$ & $48,86 \%$ & $51,14 \%$ \\
\hline Intercâmbio nas empresas & $48,96 \%$ & $51,04 \%$ \\
\hline Transferência de tecnologia (licenciamento) & $52,34 \%$ & $47,66 \%$ \\
\hline $\begin{array}{l}\text { Testes para padronização/atividades } \\
\text { de certificação da qualidade }\end{array}$ & $61,99 \%$ & $38,01 \%$ \\
\hline $\begin{array}{l}\text { Projetos de P\&D substitutos às atividades } \\
\text { de inovação da empresa }\end{array}$ & $62,79 \%$ & $37,21 \%$ \\
\hline Serviços de engenharia & $70,55 \%$ & $29,45 \%$ \\
\hline
\end{tabular}

FONTE: pesquisa de campo.

Nessa mesma direção ainda, as empresas cooperam porque têm interesse em buscar conselhos de cunho tecnológico ou consultoria com pesquisadores e/ou professores para a solução de problemas relacionados à produção e aumentar a habilidade da empresa para encontrar e absorver informações tecnológicas. Isto significa novamente que cooperam por necessidades de resolver problemas tecnológicos aplicados. Esses dois itens têm importância média/ alta para as empresas. Do lado dos GPs, esse tipo de interesse das empresar dever-se-ia refletir em melhoria de produtos industriais, melhoria de processos industriais, design e intercambio de conhecimentos ou informações, uma vez que, se referem a esse tipo de aplicação. Porem, os GPs atribuem importância nula/baixa a estes itens com exceção de intercambio de conhecimentos ou informações que importância media/alta bastante expressiva $(81,79 \%)$. Assim sendo, mais uma vez os GPs não têm interesse em cooperação para melhorias ou conhecimentos de aplicação imediata e sim não obtenção de informações e conhecimentos num sentido mais geral. Pode se entender que esses conhecimentos gerem novas pesquisas, novos conhecimentos científicos, etc., que, novamente, não estão necessariamente atrelados à resolução de problemas de produção, segundo a Figura 13. 
FIGURA 9. TRANSFERÊNCIA DE TECNOLOGIA DA UNIVERSIDADE $x$ NOVAS DESCOBERTAS CIENTÍFICAS, NOVOS PRODUTOS E ARTEFATOS, NOVOS PROCESSOS INDUSTRIAIS, PATENTES E SOFTWARE - 2006-2009

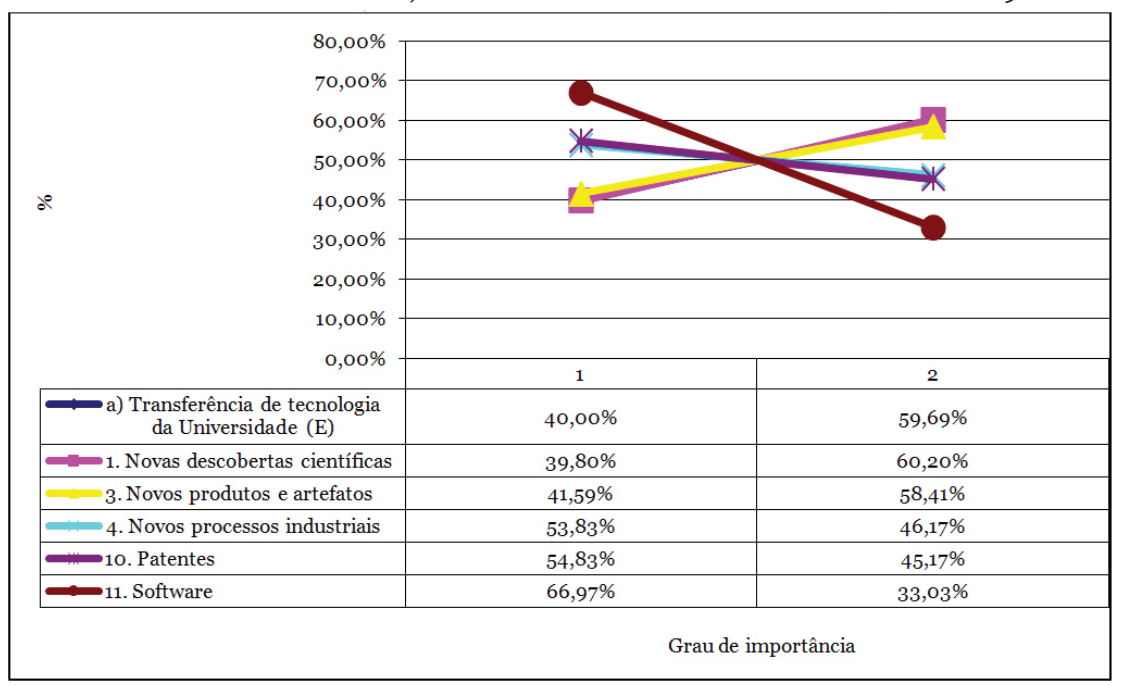

FONTE: pesquisa de campo.

FIGURA 10. INFORMAÇÕES SOBRE ENGENHEIROS OU CIENTISTAS E/OU TENDÊNCIAS DE P\&D NAS ÁREAS CIENTÍFICAS (E) x TESES E DISSERTAÇÕES, PUBLICAÇÕES E NOVAS REDES DE RELACIONAMENTO $-2006-2009$

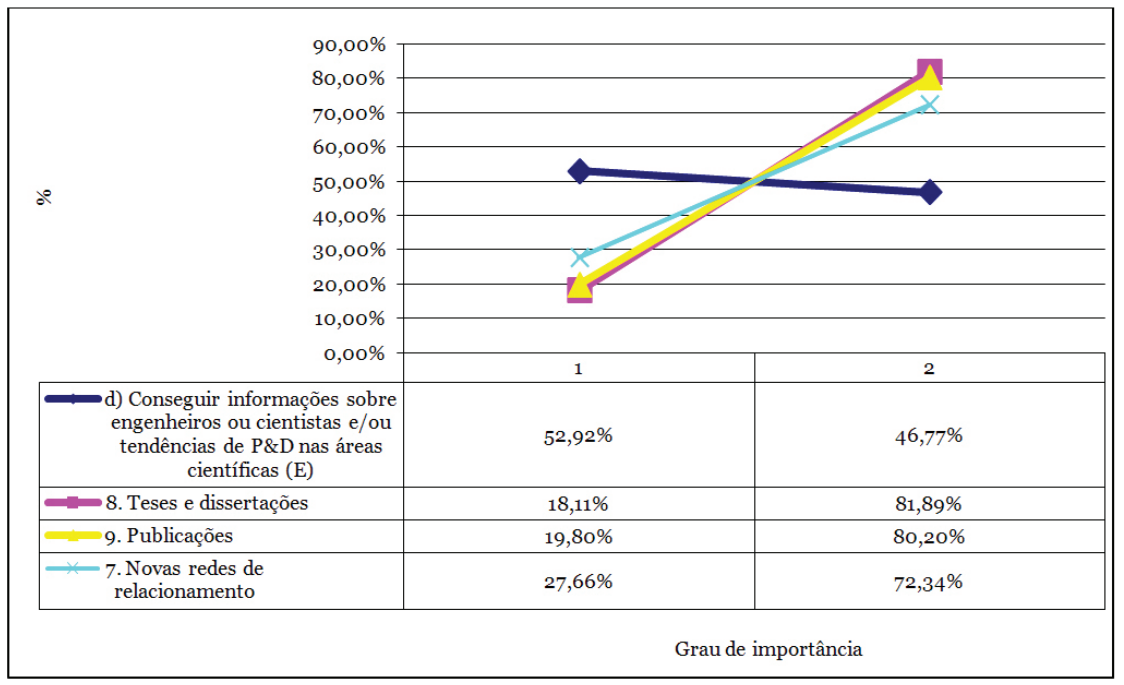

FONTE: pesquisa de campo. 
FIGURA 11. UTILIZAR RECURSOS DISPONÍVEIS NAS UNIVERSIDADES E LABORATÓRIOS DE PESQUISA (E) x EQUIPAMENTOS/ INSTRUMENTOS DE USO COMPARTILHADO (G) - 2006-2009

\begin{tabular}{|c|c|c|}
\hline \multirow{6}{*}{$\begin{array}{r}70,00 \% \\
60,00 \% \\
50,00 \% \\
40,00 \% \\
30,00 \% \\
20,00 \% \\
10,00 \% \\
0,00 \%\end{array}$} & & \multirow{2}{*}{ 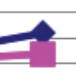 } \\
\hline & & \\
\hline & & \\
\hline & & \\
\hline & & \\
\hline & 1 & 2 \\
\hline $\begin{array}{c}\text { h) Utilizar recursos disponíveis } \\
\text { nas universidades e laboratórios } \\
\text { de pesquisa (E) }\end{array}$ & $37,85 \%$ & $61,85 \%$ \\
\hline $\begin{array}{l}\text { 4. Equipamentos/instrumentos } \\
\text { de uso compartilhado }(G)\end{array}$ & $46,07 \%$ & $53,93 \%$ \\
\hline
\end{tabular}

FONTE: pesquisa de campo.

FIGURA 12. CONTRATAR PESQUISAS COMPLEMENTARES, NECESSÁRIAS PARA AS ATIVIDADES INOVATIVAS DA EMPRESA, EM UNIVERSIDADES E INSTITUTOS, CENTROS OU LABORATÓRIOS DE PESQUISA (E) E CONTRATAR PESQUISAS QUE A EMPRESA NÃO PODE REALIZAR (E) $\mathrm{x}$ NOVOS PROJETOS DE PESQUISA, IDÉIAS PARA NOVOS PROJETOS DE COOPERAÇÃO E NOVOS PROJETOS DE PESQUISA - 2006-2009

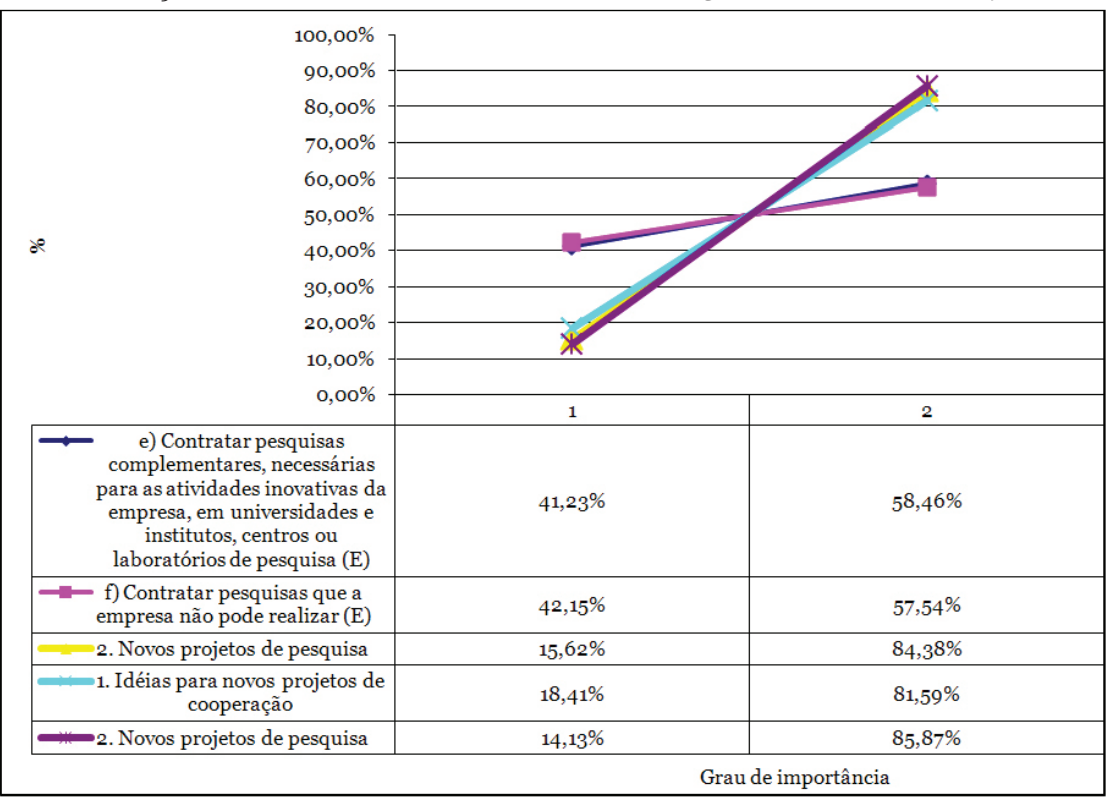

FONTE: pesquisa de campo. 
FIGURA 13. BUSCAR CONSELHOS DE CUNHO TECNOLÓGICO OU CONSULTORIA COM PESQUISADORES E/OU PROFESSORES PARA A SOLUÇÃO DE PROBLEMAS RELACIONADOS À PRODUÇÃO (E) E AUMENTARA HABILIDADE DA EMPRESA PARA ENCONTRAREABSORVER INFORMAÇÕES TECNOLÓGICAS (E) x MELHORIA DE PRODUTOS INDUSTRIAIS, MELHORIA DE PROCESSOS INDUSTRIAIS, DESIGN E INTERCÂMBIO DE CONHECIMENTOS OU INFORMACÕES - 2006-2000

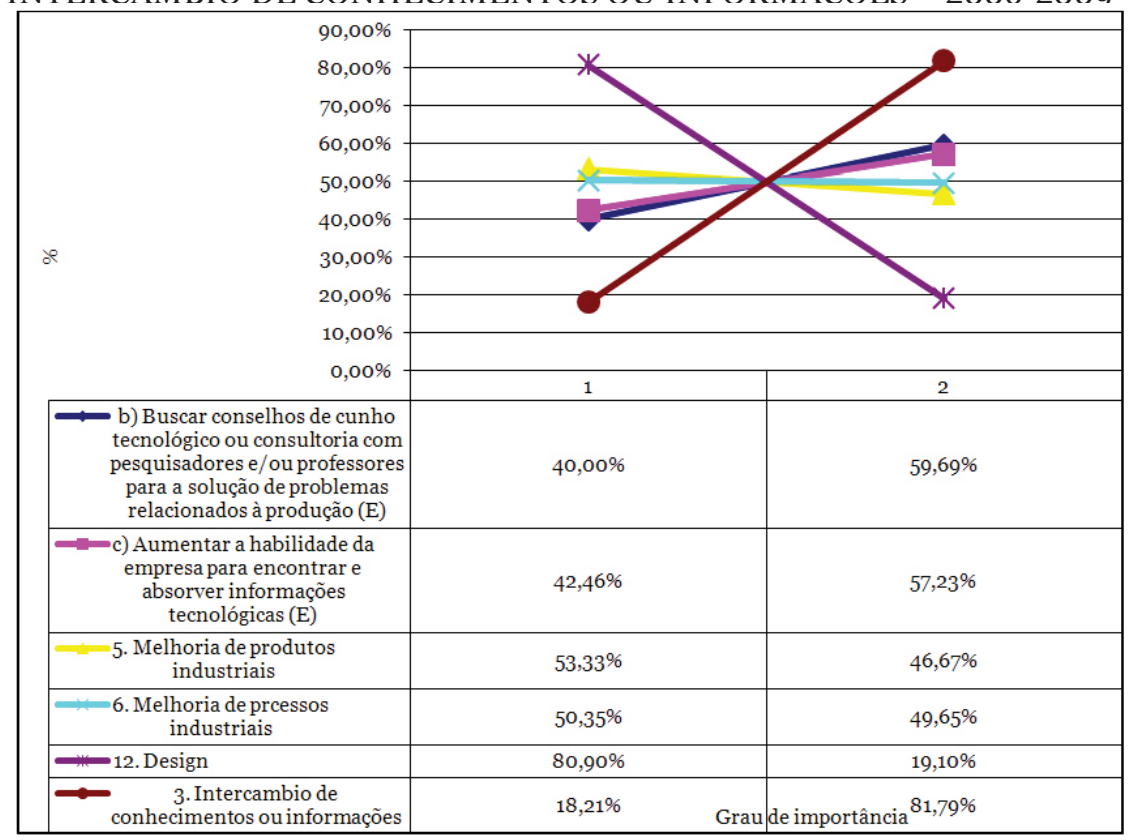

FONTE: pesquisa de campo.

\subsection{A iniciativa de se estabelecer a cooperação entre empresas e U/IP}

O primeiro aspecto a se destacar sobre a iniciativa é o fato de que não são os mecanismos institucionais da U/IP que levaram à cooperação. Assim, não é o fato da U/IP possuir mecanismos formais que buscam o relacionamento externo que leva a maior cooperação empresas com U/IP e sim fato o de que tanto empresas como GPs, por meio de mecanismos mais diretos e específicos relacionados aos seus interesses (conforme ressaltado nos gráficos anteriores) estabelecem a relação (apenas 11,08\% das respostas das empresas e 9,95\% das respostas dos GPs).

O segundo ponto interessante é que as iniciativas sempre foram mais tomadas pelas empresas do que pelos GPs. As empresas afirmaram que elas mais tomaram a iniciativa do que os GPs (52\% x 46,47\%). Por outro lado, os grupos 
afirmaram que foram eles que mais tomaram a iniciativa (32,14\% x 21,85\%) ao mesmo tempo em que afirmam que as iniciativas foram compartilhadas mais do que as empresas, de acordo com a Figura 14.

FIGURA 14. INICIATIVA DE SE ESTABELECER O RELACIONAMENTO 2006-2009

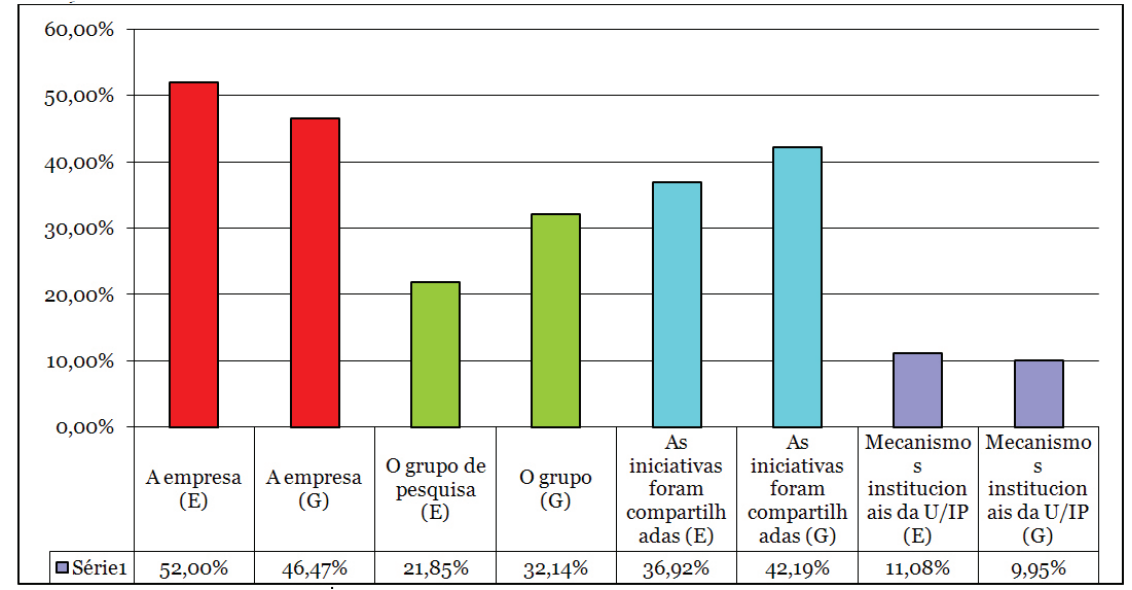

FONTE: pesquisa de campo.

\subsection{Razões dos insucessos na cooperação entre empresas e U/IP}

Grande parte dos itens listados como razão do insucesso na relação foi considerada como de importância nula/baixa para as empresas e para os GPs. Porém, em função do que foi ressaltado anteriormente - que se refere ao fato dos interesses dos GPs estarem mais voltado à produção do conhecimento cientifico e as empresas à solução de problemas - deve-se destacar que isso pode vir a ser uma das razoes de insucesso. As empresas atribuem mais importância nula/baixa a diferenças entre pontos de vista e/ou objetivos, porém, os GPs atribuem mais importância média/alta a diferença de prioridades. Assim sendo, os GPs entendem que essa diferença nos interesses, é importante e pode não atender aos seus objetivos, que é produção de conhecimento cientifico. Entretanto, apesar dessas diferenças, é como se as empresas entendessem que a busca do conhecimento cientifico por parte dos GPs passa pela interação, conhecimento aplicado e resolução de problemas. Em outros termos, é como se as empresas tivessem claro que a produção de conhecimento do tipo know-who (que elas buscam ao final) implica níveis de aprofundamento na construção desse conhecimento, como 
know-what, know-why e know-how (Raghu, 1997). Portanto, o resultado é que de uma mesma forma os objetivos dos GPs implicariam atingir os objetivos das empresas a partir da colaboração, segundo a Figura 15.

Corrobora o argumento acima outra informação da pesquisa. Para as empresas tem importância nula/baixa o fato de os pesquisadores das U/IPs são muito orientados cientificamente. Nestes termos, é pouco relevante para as empresas o fato dos GPs estarem mais interessadas nos resultados acadêmicos do que na resolução dos problemas efetivos das empresas que leva ao insucesso, porque é justamente esse interesse que acaba por dar as respostas que elas demandam. Entretanto, os GPs dão maior importância media/alta à falta de conhecimento nas empresas das atividades realizadas nas U/IP como razão do insucesso na relação, o que significa dizer que os GPs têm maiores expectativas sobre as empresas no que se refere ao intercambio acadêmico e de conhecimento quando entram na relação do que as empresas. Ao contrário, as empresas apenas buscam resolver seus problemas, mesmo que passem por evoluir no conhecimento cientifico, segundo a Figura 16.

FIGURA 15. DIFERENÇAS ENTRE PONTOS DE VISTA E/OU OBJETIVOS E X DIFERENÇA DE PRIORIDADES GP - 2006-2009

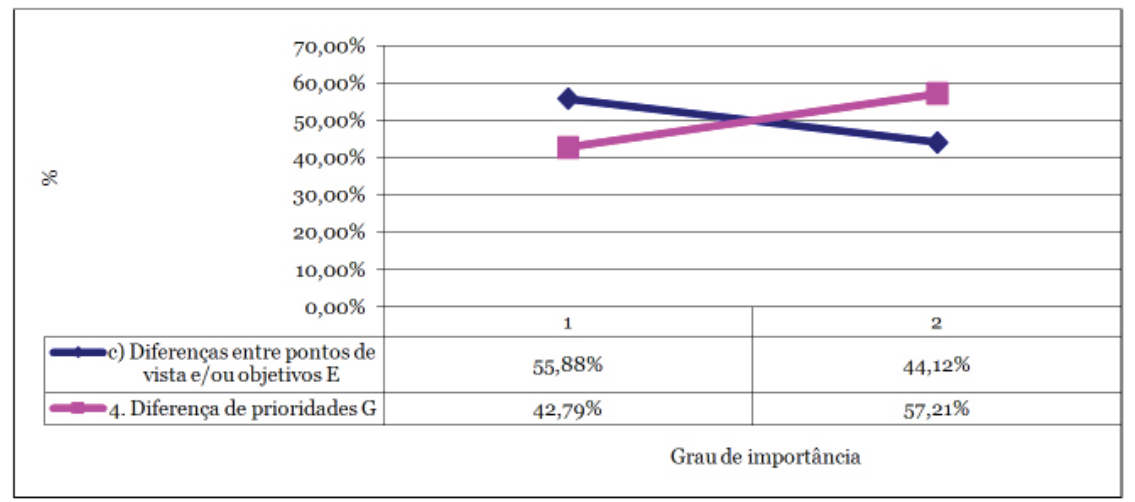

FONTE: Pesquisa de campo. 
FIGURA 16. OS PESQUISADORES DAS U/IPS SÃO MUITO ORIENTADOS CIENTIFICAMENTE (E) x FALTA DE CONHECIMENTO NAS EMPRESAS DAS ATIVIDADES REALIZADAS NAS U/IP (GP) 2006-2009

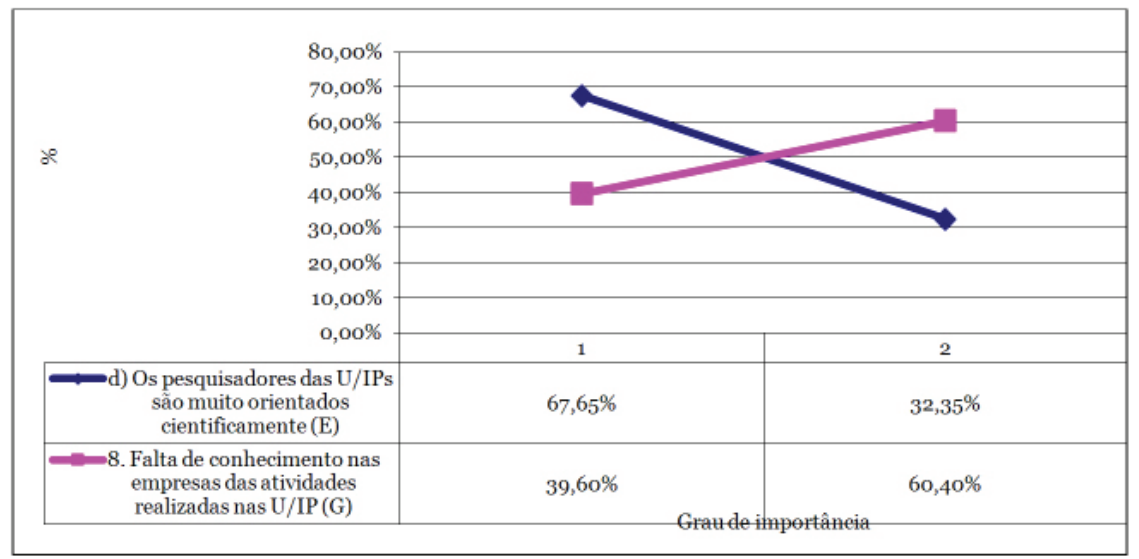

FONTE: pesquisa de campo.

\subsection{Funções da U/IP e os tipos de relacionamento}

As empresas entendem que as funções básicas da universidade são ensino, pesquisa e extensão (na pesquisa foi abordado como função social), uma vez que, atribuem maior importância média/alta a essas funções para a sua empresa. Ao mesmo tempo, quando se compara com o tipo de relacionamento que os GPs estabeleceram para estas funções há uma coincidência importante. Assim sendo, na medida em que as empresas atribuem maior importância média/alta a, por exemplo, ensino, estas tendem a buscar tipos de relacionamentos ligados a essa função. Se a empresa acredita que uma função importante é ensino, logo, estabelecer-se-á relacionamentos voltados a intercâmbio nas empresas e treinamento e cursos. Conforme a Figura 17, as empresas atribuem maior importância média/alta a ensino e ao mesmo tempo os grupos buscam se relacionar em atividades dessa natureza: primeiro treinamento e cursos, que tem a ver diretamente com ensino e depois apenas intercambio nas empresas, que tem a ver mais com aprendizado learningby-doing e menos com aprendizado formal propriamente.

Da mesma forma, as empresas atribuem mais importância alta à Pesquisa e os GPs tendem a atribuir a mesma importância média/alta a projetos de P\&D com empresas. De acordo com a Figura 18, na medida em que as empresas atribuem à função da U/IP elevada importância a pesquisa, os projetos voltados à pesquisa também assumem maior importância. Por ordem de relevância, primeiro, estão os projetos de P\&D em colaboração com a 
empresa, com resultados de uso imediato (o que corrobora a argumentação desenvolvida anteriormente de que as empresas buscam resolver problemas específicos mais aplicados de curto prazo) depois, com maior importância média/alta os GPs buscam projetos de P\&D complementares às atividades de inovação da empresa e finalmente buscam projetos de $\mathrm{P} \& \mathrm{D}$ em colaboração com empresas, sem resultados de uso imediato. A possibilidade dos GPs estabelecerem relação a partir de projetos de $\mathrm{P} \& \mathrm{D}$ substitutos às atividades de inovação da empresa existe, mas assume mais importância nula/baixa. Significa dizer que tendem a se relacionar com U/IP empresas que têm algum conhecimento relevante em pesquisa, mesmo que sejam pesquisas voltadas a resolver problemas imediatos e menos em busca do conhecimento cientifico que é a razão maior da busca de relacionamento das U/IP. Projetos de P\&D dessa natureza tendem mais a ser uma relação de mão única na direção U/ IP para empresas do que uma relação de colaboração de interação entre as competências ou busca de ativos complementares. Daí que é um tipo de projeto pouco buscado pelos GPs.

Por último, as empresas entendem que a função social da U/IP tem mais importância média/alta. Pode-se entender que essa função social se relacione a projetos de extensão universitária, que não necessariamente envolve $\mathrm{P} \& \mathrm{D}$ e sim prestação de serviço e ajuda à comunidade, que pode ou não implicar mobilização de recursos. De acordo com a Figura 19, na perspectiva dos GPs essa função social é exercida fundamentalmente por atividades de avaliações técnicas, estudos de viabilidade, gerenciamento de projetos e consultoria. Essas duas atividades assumem mais importância média/ alta para os GPs enquanto que as outras atividades, como transferência de tecnologia (licenciamento), testes para padronização/atividades de certificação da qualidade e serviços de engenharia que também teriam mesma relevância assumem mais importância nula/baixa. Assim sendo, os GPs não estão interessados em estabelecer relações que implique essas atividades. A explicação para isso continua na mesma linha argumentada anteriormente. O licenciamento implica a existência de patentes e como já foi visto patentes não é um produto relevante na relação. Ademais as outras duas atividades se relacionam mais a prestação de serviços de resolução de problemas imediatos e não $\mathrm{P} \& \mathrm{D}$ que implique novos conhecimentos. 
FIGURA 17. ENSINO (E) x INTERCÂMBIO NAS EMPRESAS E TREINAMENTO E CURSOS (GP) 2006-2009

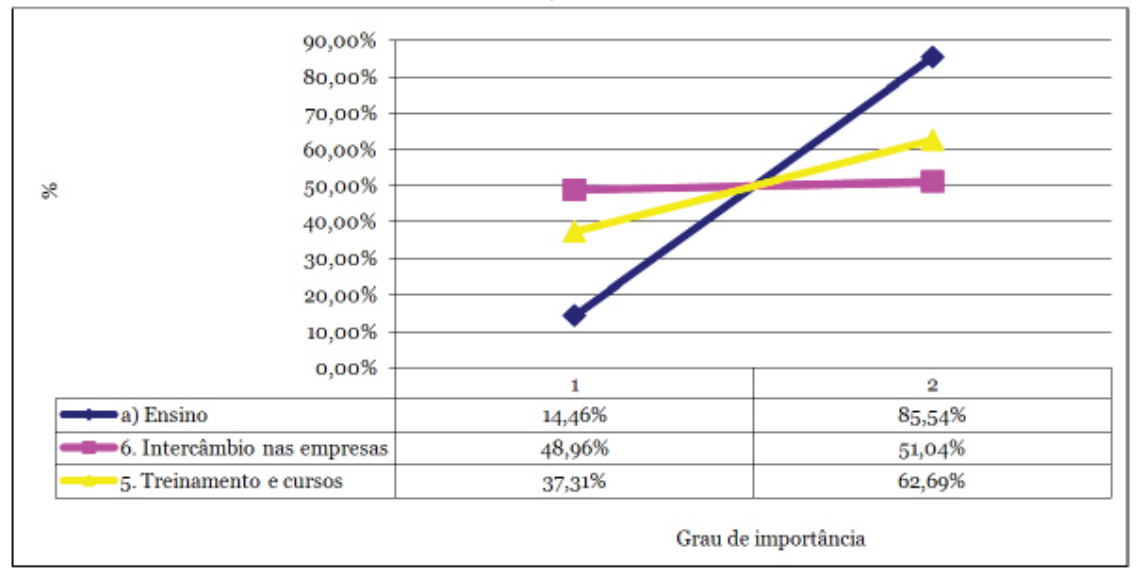

FONTE: pesquisa de campo.

FIGURA 18. PESQUISA (E) x PROJETOS DE P\&D EM COLABORAÇÃO COM A EMPRESA, COM RESULTADOS DE USO IMEDIATO; PROJETOS DE P\&D EM COLABORAÇÃO COM EMPRESAS, SEM RESULTADOS DE USO IMEDIATO; PROJETOS DE P\&D COMPLEMENTARES ÀS ATIVIDADES DE INOVAÇÃO DA EMPRESA E PROJETOS DE P\&D SUBSTITUTOS ÀS ATIVIDADES DE INOVAÇÃO DA EMPRESA (GP) - 2006-2009

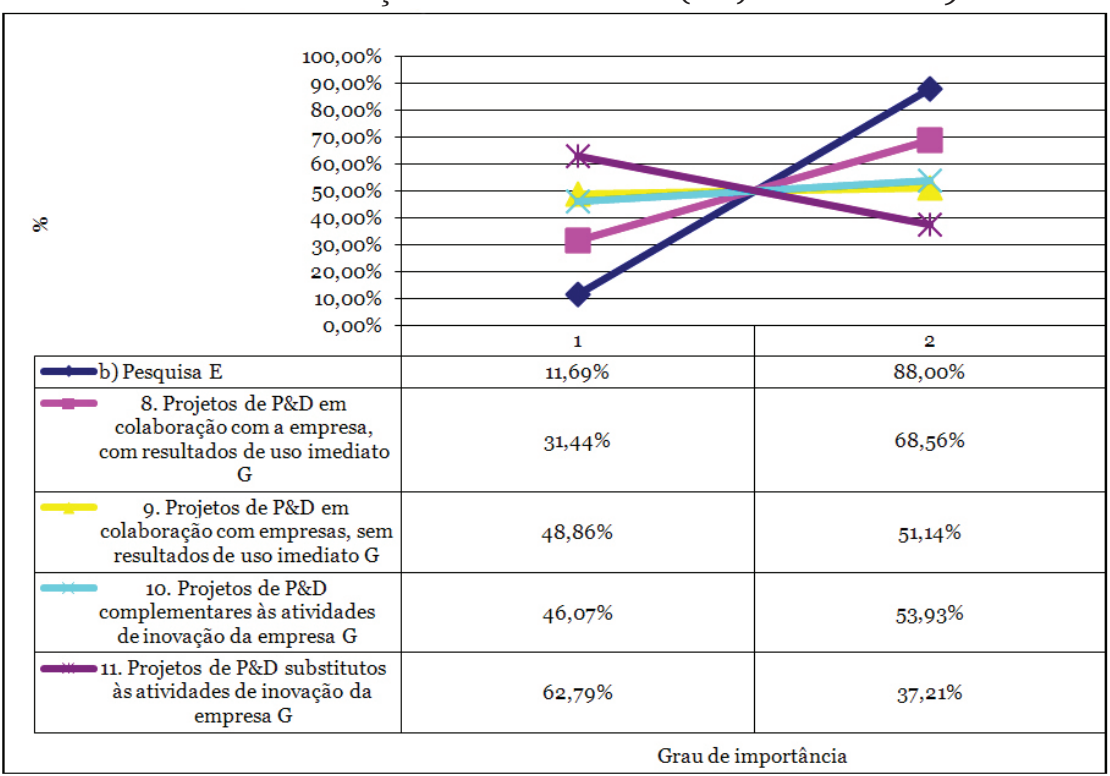

FONTE: pesquisa de campo. 
FIGURA 19. SOCIAL (E) x TRANSFERÊNCIA DE TECNOLOGIA (LICENCIAMENTO); TESTES PARA PADRONIZAÇÃO /ATIVIDADES DE CERTIFICAÇÃO DA QUALIDADE; SERVIÇOS DE ENGENHARIA; AVALIAÇÕES TÉCNICAS, ESTUDOS DE VIABILIDADE, GERENCIAMENTO DE PROJETOS E CONSULTORIA (GP) 2006-2009

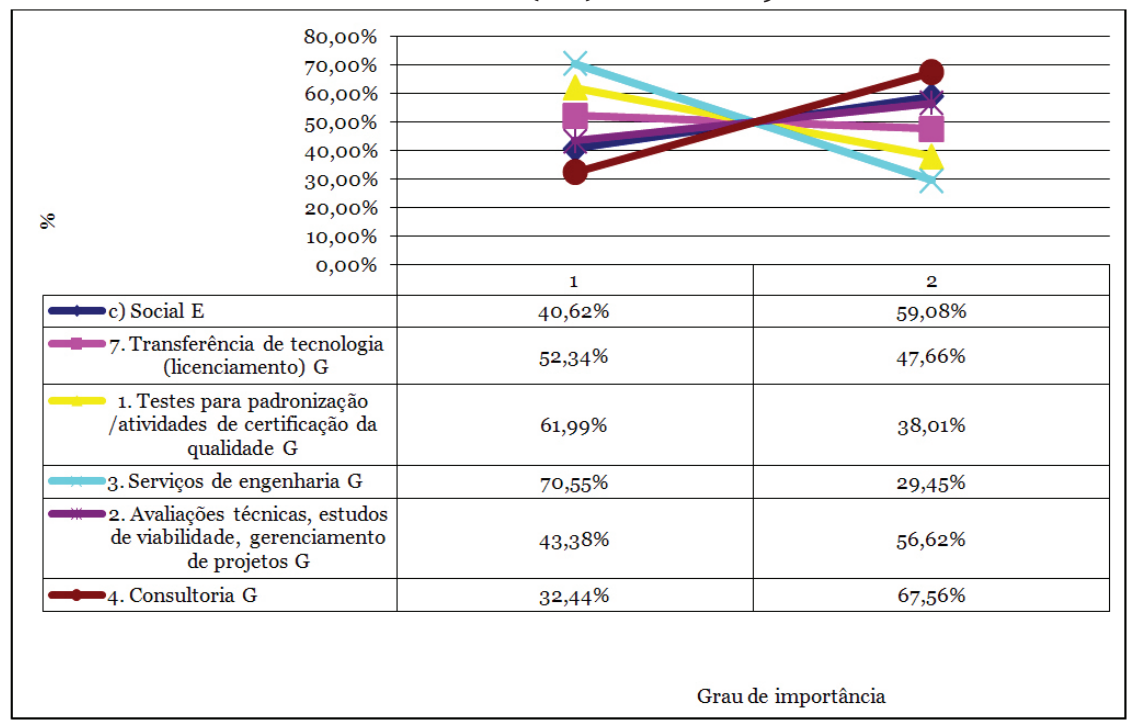

FONTE: pesquisa de campo.

\subsection{Contribuição das U/IP para as empresas e o número de GPs por área do conhecimento que reportam interações}

Supostamente as áreas do conhecimento com maior número de GPs que se relacionam com empresas, seriam as áreas que mais deveriam interagir com as empresas, uma vez que, são as que mais possuem pesquisas sendo realizadas. Entretanto, isso não é verdadeiro. Na perspectiva das empresas as áreas que mais contribuem (maior importância média/alta por área do conhecimento) não são as que possuem maior número de GPs que se relacionam com U/IP. Desse modo, significa dizer que há áreas com menor número de GPs, cujas áreas contribuem proporcionalmente mais com as empresas, segundo as próprias empresas. É compreensível que não haja uma correlação estreita entre o número de GPs e áreas do conhecimento que contribuem com as empresas, em função de que os GPs não se formam em decorrência da relação com U/IP. A pesquisa dentro dessas instituições se forma com autonomia e, como ressaltado acima é em função da busca do conhecimento cientifico e não da relação com empresas que elas se estabelecem. 
TABELA 2. CONTRIBUIÇÃO PARA AS EMPRESAS x NÚMERO DE GPS POR ÁREAS DO CONHECIMENTO - 2006-2009

\begin{tabular}{|c|c|c|c|c|}
\hline Área do Conhecimento & $1+2$ & $3+4$ & Área do Conhecimento & $\begin{array}{c}\mathrm{n}^{\mathrm{o}} \mathrm{de} \\
\text { GPs }\end{array}$ \\
\hline 1 Eng. de Mat. e Metal. & $73,85 \%$ & $25,85 \%$ & 1 Ciências Biológicas & 107 \\
\hline 2 Med. Veterinária & $75,38 \%$ & $24,31 \%$ & 2 Agronomia & 86 \\
\hline 3 Computação & $75,69 \%$ & $24,00 \%$ & 3 Eng. Elétrica & 62 \\
\hline 4 Engenharia Mecânica & $76,31 \%$ & $23,38 \%$ & 4 Eng. Mat. e Metal. & 57 \\
\hline 5 Engenharia de Minas & $76,92 \%$ & $22,77 \%$ & 5 Eng. Civil & 46 \\
\hline 6 Engenharia Elétrica & $76,92 \%$ & $22,77 \%$ & 6 Computação & 44 \\
\hline 7 Agronomia & $77,54 \%$ & $22,15 \%$ & 7 Eng. Mecânica & 44 \\
\hline 8 Química & $81,48 \%$ & $17,59 \%$ & 8 Química & 41 \\
\hline 9 Ciências Biológicas & $83,38 \%$ & $16,31 \%$ & 9 Geociências & 37 \\
\hline 10 Engenharia Civil & $87,08 \%$ & $12,62 \%$ & 10 Medicina & 35 \\
\hline 11 Ciência e Tec. de Alim. & $88,00 \%$ & $11,69 \%$ & 11 Eng. Química & 29 \\
\hline 12 Engenharia Química & $89,23 \%$ & $10,46 \%$ & 12 C\&T de Alimentos & 25 \\
\hline 13 Medicina & $90,77 \%$ & $8,92 \%$ & 13 Med. Veterinária & 25 \\
\hline 14 Física & $92,31 \%$ & $7,38 \%$ & 14 Física & 18 \\
\hline 15 Desenho Industrial & $93,85 \%$ & $5,85 \%$ & 15 Eng. de Minas & 7 \\
\hline 16 Geociências & $94,77 \%$ & $4,92 \%$ & 16 Desenho Industrial & 4 \\
\hline 17 Matemática & $94,77 \%$ & $4,92 \%$ & 17 Matemática & 3 \\
\hline
\end{tabular}

FONTE: pesquisa de campo. 
Por outro lado, pode se entender que as áreas com maior número de GPs que contribuem relativamente pouco com empresas o fazem de forma secundária. Isto é, os GPs possuem suas rotinas de pesquisa e a relação passa a ser um fato relativamente menos relevante das pesquisas. Por exemplo, a área de Ciências Biológicas que possui o maior número de GPs (107), de acordo com as empresas, tem apenas contribuição pouco relevante (está em $9^{\circ}$ lugar termos de áreas que contribuem), conforme expresso na Tabela 2. Isso significa que a área supostamente tem muitas pesquisas, mas as que contribuem com as empresas são relativamente poucas. Em outros termos, as pesquisas que são realizadas não interessam as empresas diretamente, seja porque não são aderentes à sua realidade em função de que as empresas buscam solução de problemas imediatos ou porque os GPs estão pesquisando algo que não tem a ver com desenvolvimento tecnológico específico e mais tem a ver com a pesquisa básica. Seja por uma ou outra razão, dada a discrepância entre numero de GPs e áreas que mais contribuem com as empresas haveria amplo espaço para que todos os GPs ampliassem sua contribuição com as empresas.

\section{Conclusão}

Como destacado ao longo da pesquisa as evidencias encontradas corroboram a ideia que a interação universidade-empresa é importante para o processo inovativo em geral para as empresas brasileiras e tem uma motivação bi-direcional.

Para os dois atores as patentes são consideradas como de baixa importância como fonte de informação para as atividades inovativas e para o aumento de conhecimento das empresas sobre outras empresas, universidades e institutos de pesquisas (IP). Da mesma forma, as patentes não são mecanismos relevantes para os GPs transferirem conhecimento às empresas. Por outro lado, as empresas e os GPs consideram que a troca informal de informações e publicações e relatórios são relevantes para a aquisição de informações nos dois sentidos. As empresas usam muito os resultados produzidos pelas U/IP ao mesmo tempo em que isso resulta em benefícios relevantes para os GPs, com exceção de novos processos industriais

As empresas colaboram porque buscam algum produto/serviço/conhecimento que a relação pode produzir. Do lado das U/IP, os GPs também somente interagem se ela implicar resultados e benefícios para os grupos de pesquisa. O relacionamento U-E é importante também, pois possibilita a geração de temas concretos e aplicados para a produção de teses e dissertações, publicações e a formação de novas redes de relacionamento. Enquanto as empresas cooperam para resolver seus problemas em termos até de pesquisa aplicada, os GPs cooperam para produzir novos conhecimentos. Os interesses têm um 
foco um pouco diferenciado entre as duas instâncias, mas a forma de se chegar a seus objetivos específicos implica em cooperação.

Sintetizando o principal aspecto a se destacar sobre a iniciativa de se estabelecer a cooperação entre empresas e U/IPé o fato de que não são os mecanismos institucionais da U/IP que levam à cooperação, e sim fato o de que tanto empresas como GPs nas universidades e nos institutos de pesquisa , por meio de mecanismos mais diretos e específicos relacionados aos seus interesses concretos estabelecem a interação entre eles.

Na perspectiva das empresas as áreas que mais contribuem (maior importância média/alta por área do conhecimento) não são as que possuem maior número de GPs que se relacionam com U/IP. Enquanto as Ciências Biológicas e Agronomia reportaram as maiores interações, do lado das empresas a Ciências Biológicas e Agronomia aparecem apenas em uma situação intermediaria nas prioridades das empresas. Os setores de Engenharia, Medicina Veterinária e Computação são os principais segmentos que reportaram interações por parte das empresas. 


\section{Referências bibliográficas}

COHEN, W. M.; NELSON R. R.; WALSH, J. P. (2002). "Links and Impacts: The Influence of Public Research on Industrial R\&D." Management Science, 48 (1); p. 1-23.

FERNADES A. C.; da SILVA, A. S.; SUZIGAN, W.; CHAVES, C. V.; ALBUQUERQUE, E. (2010). "Academy-industry links in Brazil: evidence about channels and benefits for firms and researches." Science and Public Policy, 37 (7); p. 485-498.

GARUD, R. (1997). "On the Distinction between know-how, know-why and know-what." Advances in strategic management, 14; p. 81-101.

GINARTE, J. C.; PARK, W. G. (1997). "Determinants of patent rights: A cross-national study.” Research Policy, 26; p. 283-301.

GIBBONS, M. \& JONSTON, R. (1975). "The roles of science in technological innovation.” Research Policy, 3; p. 220-242.

LALL, S. \& ALBALADEJO, M. (2003). "Indicators of the relative importance of IPRs in developing countries." Research Policy, 32; p. 1657-1680.

NELSON; R. (1990). "Capitalism as engine of Progress." Research Policy, 19; p. 193-214.

PULIDO, L. J. (2011). Inovação Tecnológica e Desenvolvimento Econômico. [Monografia]. Pontifícia Universidade Católica de Minas Gerais (PUC/MG). Belo Horizonte.

STOKES, D. E. (1997). Pasteur' Quadrant: Basic Science and Techological Innovation. Washington D.C.: Brookings Institution Press.

SUZIGAN W.; ABUQUERQUE E. M. (2011). "The undersestimeted role of university for the brazilian system of innovation." Revista de Economia Política, 31 (1); p. 3-35.

WORLD INTELLECTUAL PROPERTY INDICATORS. (2010). World Intellectual Property Indicators. URL [on-line]: http://www.wipo.int/ ipstats/en/statistics/patents/. Acesso em: 10 de out. de 2011. 